\title{
Comparison of bronchial challenge with ultrasonic nebulized distilled water and hypertonic saline in children with mild-to-moderate asthma
}

\author{
C. Wojnarowski*, K. Storm Van's Gravesande*, J. Riedler**, \\ I. Eichler*, C. Gartner*, T. Frischer*
}

Comparison of bronchial challenge with ultrasonic nebulized distilled water and hypertonic saline in children with mild-to-moderate asthma. C. Wojnarowski, K. Storm Van's Gravesande, J. Riedler, I. Eichler, C. Gartner, T. Frischer. (CERS Journals Ltd 1996.

ABSTRACT: There is still controversy about the most suitable method to measure bronchial hyperresponsiveness in children. In epidemiological surveys, nonisotonic aerosols are being used increasingly for bronchial provocation testing. Our aim was to study the acceptability, safety and correlation between two published bronchial challenge tests.

Two standardized protocols - the inhalation of hypertonic saline (HS) and ultrasonically-nebulized distilled water (UNDW) - were performed in 36 children: 19 patients with the clinical diagnosis of mild-to-moderate asthma (7-12 yrs of age), and 17 control subjects $(8-18$ yrs of age). HS challenge involved stepwise inhalation of $4.5 \%$ saline (for $0.5,1,2,4$ and 8 min), whereas challenge with UNDW was performed as a single step protocol with $10 \mathrm{~min}$ inhalation of cold UNDW. Asthma medication was withheld prior to challenge testing.

Thirty five subjects completed both challenge tests (one asthmatic patient did not return after UNDW challenge) in random order within a 7 day time interval. For HS a $\geq 15 \%$ reduction in forced expiratory volume in one second (FEV1) from baseline was considered a positive response, and for UNDW a $\geq 10 \%$ decrease. In 13 of the 19 asthmatic patients, but in none of the controls, a positive response was observed for UNDW. Fifteen out of 18 patients and one control subject had a positive response to HS. Twelve out of $\mathbf{1 8}$ asthmatic children responded to both challenges, three responded only to HS and three had no response to either challenge. There was a negative correlation between log provocative dose causing a $15 \%$ reduction in FEV1 (PD15) after HS and the maximum fall in FEV1 after UNDW $\left(r_{\mathrm{s}}=\right.$ $-0.63 ; p<0.005)$. The HS challenge had a lower acceptability than challenge with UNDW due to the unpleasant salty taste of HS. However, this did not inhibit the completion of the tests in any subject.

The results of this study suggest a good correlation between response to hypertonic saline and ultrasonically-nebulized distilled water in children with mild-tomoderate asthma. A multiple step protocol might be safer when applied in field studies involving children.

Eur Respir J., 1996. 9, 1896-1901.
*University Children's Hospital, Vienna, Austria. **Children's Hospital, Salzburg, Austria.

Correspondence: T. Frischer

University Children's Hospital

Währinger Gürtel 18-20

1090 Vienna

Austria

\section{Keywords: Asthma}

bronchial provocation

hypertonic saline

ultrasonically nebulized distilled water

Received: January 41996

Accepted after revision May 281996
Evidence has accumulated that the incidence of asthma has increased over the past decades [1], mainly among children. In order to study time trends in asthma epidemiology, one has to rely on standardized tests to characterize the disease. Since there is no gold standard of diagnosis and since asthma in children is a heterogeneous disease, information from questionnaire data, allergy testing and assessment of nonspecific bronchial hyperresponsiveness (BHR) is compiled to characterize the individual. Whilst there is growing consensus in standardization of questionnaires [2], there is still controversy about the most suitable method to assess BHR in children in epidemiological studies [3]. Both pharmacological and nonpharmacological tests have been used [4-16] but, since controversial data concerning the relationship between the two and among nonpharmacological tests have been reported, it is difficult to compare results between studies [4, 6, 8-12]. Regarding time trends, only when an identical protocol has been used at different points in time can valid conclusions be drawn [13].

Pharmacological tests, such as methacholine or histamine challenges, offer a relatively high sensitivity but there is also a high rate of false positive tests [3]. Nonpharmacological challenge tests involve provocation with cold air [14], exercise [15], and inhalation of nonisotonic aerosols [8]. In general, these methods provide a high specificity but somewhat less sensitivity. Whereas some tests require sophisticated equipment (cold air) or a high degree of compliance (exercise), which is often difficult to obtain in teenagers, inhalation of nonisotonic aerosols is easy to perform and requires minimal equipment and personnel. For both the inhalation of 
ultrasonically-nebulized distilled water (UNDW) $[13,16]$ and hypertonic saline (HS) [4], population-based studies in children have been published [7, 13, 16].

In a clinical setting, we wanted to study whether the results obtained by these two published protocols correlate, which is what we would expect, conceptually, since a similar stimulus is exerted on the bronchial mucosa. To our knowledge, no such comparison has been made in children so far. Given a high correlation between the two methods, the issues of safety, acceptability and duration of the test would then influence the choice of a specific test for use in further studies.

\section{Methods}

\section{Normal controls}

Baseline characteristics of the study population are presented in table 1 . The control subjects were 17 children, 5 males and 12 females, aged 8-18 yrs (mean \pm sD age $16 \pm 3$ yrs), who were recruited from the Paediatric and Orthopaedic out-patient clinic of the University Hospital of Vienna. None of these children had a history of wheeze or chronic cough, and none had ever required the use of a beta-receptor agonist. There was no history of respiratory tract infection during the 4 weeks prior to the study. None of the children had a personal or family history of atopy or asthma.

\section{Patients with asthma}

Nineteen patients ( 14 males and 5 females) were recruited from the Asthma out-patient clinic at the University Children's Hospital of Vienna. They were aged 7-12 yrs (mean \pm sD $11 \pm 3 \mathrm{yrs}$ ). All of them had a clinical diagnosis of mild-to-moderate asthma corresponding to the American Thoracic Society (ATS) criteria [17] for more than 1 year, and documented reversible airway obstruction (15\% increase in forced expiratory volume in one second (FEV1) after inhalation of salbutamol and/or a BHR documented as a positive methacholine challenge [18]. Sixteen patients used inhaled steroids (budesonide) on a regular basis, 13 patients were prescribed short-acting $\beta_{2}$-agonist inhalations, six patients received long-acting inhaled bronchodilators and one patient required antihistamines. Asthma medication was withheld prior to challenge testing (cromoglycate and short-acting inhaled bronchodilators for at least $6 \mathrm{~h}$, topical steroids and longacting inhaled bronchodilators for at least $24 \mathrm{~h}$, theophyllines for at least $12 \mathrm{~h}$, and antihistamines for at least $48 \mathrm{~h}$ ). At the time of the study, symptoms were well controlled and FEV1 was greater than $75 \%$ of predicted value. There

Table 1. - Baseline characteristics of the study population prior to first challenge

\begin{tabular}{llcc}
\hline & $\begin{array}{c}\text { Patients } \\
(\mathrm{n}=19)\end{array}$ & $\begin{array}{c}\text { Controls } \\
(\mathrm{n}=17)\end{array}$ \\
\hline Age $\quad$ yrs & $11 \pm 3$ & $16 \pm 3$ \\
Sex & M/F & $14 / 5$ & $5 / 12$ \\
FEV $1 \%$ pred & $89 \pm 11$ & $114 \pm 11$ \\
FVC $\%$ pred & $105 \pm 8$ & $110 \pm 9$ \\
\hline
\end{tabular}

Values are presented as mean \pm SD. FEV1: forced expiratory volume in one second; FVC: forced vital capacity; \% pred: percentage of predicted value; M: male; F:female. was no history of respiratory tract infection during the 4 weeks prior to the study. Asthma severity was assessed by a standardized score [19], allowing a classification of six severity groups in which a score of 1 represented minor symptoms and 6 represented worst symptoms.

\section{Study design}

The study was a randomized, cross-over study. Patients were randomly assigned to start with either UNDW or HS. Children were asked to attend the lung function laboratory at the same time of day on two occasions, separated by 7 days, to perform both bronchial provocation tests. Asthmatics and healthy subjects followed the same protocol. The clinical status of the patients was initially evaluated by a paediatric pulmonologist, and the parents completed a questionnaire on current medication and the frequency and severity of their child's asthma. A visual analogue scale (VAS) was used to determine the acceptability of the two protocols. The VAS was mailed approximately 1-2 weeks after the completion of the study. For each of the two tests, children were asked whether it was experienced as being pleasant or unpleasant (scale 0-4). The study protocol was approved by the University Ethics Committee on human subjects in medical research. Parental written informed consent was obtained prior to enrolment after detailed study description.

\section{Pulmonary function}

Pulmonary function tests were performed at each visit. Forced vital capacity (FVC) and FEV1 were recorded in the form of a maximum flow-volume curve (Masterlab; E. Jaeger, Germany) according to ATS standards [20]. Results were expressed as percentage predicted based on accepted reference standards [21]. Bronchodilatation via inhalation of salbutamol was performed when judged necessary by the physician attending the tests. In all patients, recovery from the challenges was followed by careful observation for $30 \mathrm{~min}$.

\section{Challenge with hypertonic (4.5\%) saline (HS)}

HS challenge tests were performed using a protocol developed by SMITH and ANDERSON [4] with some minor modifications as used in a recent population survey by RIEDLER et al. [7]: a solution of $4.5 \%$ HS was nebulized via a Devilbiss Ultraneb 2000 ultrasonic nebulizer, connected to $60 \mathrm{~cm}$ of corrugated aerosol tubing and a threeway nonrebreathing valve (Hans Rudolph No. 1410). The nebulizer canister was filled with $150 \mathrm{~mL}$ of $\mathrm{HS}$ and was refilled after the final challenge step. The output of the nebulizer was set to maximum position, guaranteeing an output ranging 1.4-4.6 $\mathrm{mL} \cdot \mathrm{min}^{-1}$ [22]. During the challenge, the nebulizer output was kept constant and the dose of saline increased successively by doubling the inhalation time, starting with 0.5 then $1,2,4$ and 8 min with subjects inhaling at tidal volumes. FEV1 measurements were made in duplicate $60 \mathrm{~s}$ after each challenge step. Where two successive FEV1 values differed by more than $5 \%$, a third measurement was taken and, according to ATS criteria, the best of two reproducible (and acceptable) FEV1 was used for calculation. The challenge was 
terminated when the FEV1 had fallen by at least $15 \%$ of baseline, or a cumulative inhalation time of $15.5 \mathrm{~min}$ had been achieved. The nebulizer canister plus tubing was weighed on an electronic balance (Mettler, SM-6000) before challenge and after the final step to assess the total amount of aerosol nebulized. The mean output during the provocation was $2.5 \mathrm{~mL} \cdot \mathrm{min}^{-1}$ with a SD of 0.84 $\mathrm{mL} \cdot \mathrm{min}^{-1}$.

\section{Challenge with UNDW}

The challenge tests were performed according to a published protocol $[5,13,16]$. Aerosols of distilled water were generated by an ultrasonic nebulizer (Habel M608; Vienna, Austria), connected to $20 \mathrm{~cm}$ of corrugated aerosol tubing and a mouthpiece with a three-way valve to permit the expired air to be exhaled into the atmosphere. The water canister was filled with $150 \mathrm{~mL}$ cold $\left(4^{\circ} \mathrm{C}\right)$ distilled water. A constant water temperature was maintained by adding ice cubes to the canister after each challenge test. The patients, with noseclips attached, had to breath tidally through the mouthpiece inhaling the aerosol continuously over $10 \mathrm{~min}$. Immediately and $5 \mathrm{~min}$ after the inhalation, maximum expiratory flow-volume curves were recorded. A positive response was defined as a $\geq 10 \%$ decrease in FEV1 occurring after UNDW inhalation. The water volume output during the provocation was $1.0 \mathrm{~mL} \cdot \mathrm{min}^{-1}$ (SD 0.37), delivering an aerosol with a mass median aerodynamic diameter of $8 \mu \mathrm{m}$ (as described by the manufacturer).

\section{Data analysis}

A $15 \%$ reduction in FEV1 from baseline was considered a positive response to HS. Furthermore, the provocation dose causing a $15 \%$ reduction in FEV1 (PD15) was calculated by linear interpolation of individual doseresponse curves, plotting the \% fall in FEV1 from baseline against the cumulative dose of aerosol delivered $(\mathrm{mL})$. PD15 values were log-transformed to achieve a normal distribution. A positive UNDW challenge was defined as a $\geq 10 \%$ decrease in FEV1. Spearman's rank correlation test was used to assess the association between variables. Analyses were performed using the Statistical Analysis System (SAS) software package (version 6.04).

\section{Results}

Thirty six children were enrolled: 17 control subjects without any personal or family history of atopy or asthma and 19 patients with mild-to-moderate asthma. By means of allergy tests, as available from medical records (skin tests, specific immunoglobulin E (IgE)), three asthmatic patients were nonatopic, two patients were sensitized to seasonal, 9 to perennial and 5 to combined allergens. Regarding the asthma severity score, seven patients were considered to have a symptom severity of first grade, five patients of second, four patients of third, two patients of fourth, and one patient of fifth grade. All asthmatic patients were able to withhold their medication as required.

Children were randomly allocated to one of the two tests: 18 children started with the HS- and 18 with the UNDW-challenge protocol. Seventeen percent of the challenge tests were performed in the morning and $83 \%$ in the afternoon. One asthmatic child withdrew from the study after the first challenge test (UNDW) because of unwillingness to return for a second provocation. Thirty five subjects completed both challenge tests. Another asthmatic patient failed to repeat a lung function test $5 \mathrm{~min}$ after the UNDW-challenge because of dyspnoea, and one control subject did not complete the flow-volume curve $5 \mathrm{~min}$ after the UNDW-challenge because of lack of compliance.

The VAS was returned by 24 children. The average score for HS was 2.9 (SD 0.85) and for UNDW 1.8 (SD 1.09), suggesting lower acceptability for the HS-challenge (Wilcoxon sign rank test: $\mathrm{p}<0.001$ ). The inhalation of HS provoked a transient coughing and irritation of the throat in 29 of the 35 subjects, excessive saliva production in 21 , and most of the children complained about an unpleasant salty taste. However, this did not inhibit the completion of the tests in any subject. The inhalation of UNDW provoked coughing in 28 subjects in the first minute of the bronchial challenge.

There were no significant differences in baseline lung function assessed before the two challenges in asthmatic patients and controls (table 1). For asthmatic children average FEV1 was 2.03 (SD 0.5) L at the first challenge and 1.99 (SD 0.4) L at the second. Corresponding values for controls were 3.42 (SD 0.8) L at the first challenge and 3.48 (SD 0.8 ) at the second, respectively.

A positive response for UNDW was observed in 13 of the 19 asthmatic patients compared to none of the controls. Six patients did not respond to UNDW challenge. In 12 asthmatics, the positive response was observed immediately after the provocation, the largest fall in FEV1 being $42 \%$ in one patient (No. 14) and $38 \%$ in another (No. 6) (table 2). Their bronchial obstruction was

Table 2. - Individual PD15 (HS), maximum percentage fall in FEV 1 after UNDW and current medication in children with asthma

\begin{tabular}{lccc}
\hline $\begin{array}{l}\text { Pt } \\
\text { No. }\end{array}$ & $\begin{array}{c}\text { Current } \\
\text { medication }\end{array}$ & $\begin{array}{c}\text { PD15 (HS) } \\
\mathrm{mL}\end{array}$ & $\begin{array}{c}\text { Maximum fall in } \\
\text { FEV1 after UNDW } \\
\%\end{array}$ \\
\hline 1 & $\mathrm{~B}, \mathrm{~s} \beta_{2}$-A & $*$ & 8 \\
2 & $\mathrm{~B}, 1 \beta_{2}$-A & 13.3 & 9 \\
3 & $\mathrm{~B}, \mathrm{~s} \beta_{2}$-A & $*$ & 9.8 \\
4 & $\mathrm{~B}, \mathrm{~s} \beta_{2}$-A & $*$ & 9 \\
5 & $\mathrm{~B}$ & 0.8 & 10 \\
6 & $1 \beta_{2}-\mathrm{A}$ & 1.7 & 38 \\
7 & $\mathrm{~B}, \mathrm{~s} \beta_{2}-\mathrm{A}$ & 2.2 & 19 \\
8 & $\mathrm{~B}, \mathrm{~s} \beta_{2}-\mathrm{A}, 1 \beta_{2}-\mathrm{A}$ & 2.5 & 24 \\
9 & $\mathrm{~B}, \mathrm{~s} \beta_{2}-\mathrm{A}, \mathrm{AH}$ & 6.0 & 6 \\
10 & $\mathrm{~B}, \mathrm{~s} \beta_{2}-\mathrm{A}$ & 2.6 & 21 \\
11 & $\mathrm{~B}, \mathrm{~s} \beta_{2}-\mathrm{A}$ & 1.4 & 24 \\
12 & $\mathrm{~B}, \mathrm{~s} \beta_{2}-\mathrm{A}$ & 1.0 & 33 \\
13 & $\mathrm{~B}, 1 \beta_{2}-\mathrm{A}$ & 1.3 & 22 \\
14 & $\mathrm{~B}, 1 \beta_{2}-\mathrm{A}$ & 3.0 & 42 \\
15 & $\mathrm{~B}, \mathrm{~s} \beta_{2}-\mathrm{A}, 1 \beta_{2}-\mathrm{A}$ & 10.5 & 11 \\
16 & $\mathrm{~B}$ & 4.4 & 2 \\
17 & $\mathrm{~B}, \mathrm{~s} \beta_{2}-\mathrm{A}$ & 2.2 & 17 \\
18 & $\mathrm{~s} \beta_{2}-\mathrm{A}$ & 3.5 & 13 \\
19 & $\mathrm{~s} \beta_{2}-\mathrm{A}$ & $* *$ & 14 \\
\hline
\end{tabular}

*: Patients Nos. 1, 3 and 4 did not respond after a cumulative HS-inhalation time of $15.5 \mathrm{~min}$; **: patient No. 19 did not return for the HS-challenge. Pt: patient; HS: hypertonic saline; UNDW: ultrasonically-nebulized distilled water; FEV1: forced expiratory volume in one second; PD15 (HS): provocation dose of $\mathrm{HS}$ causing a $15 \%$ fall in $\mathrm{FEV}_{1}$; B: inhalation of budesonide; $1 \beta_{2}$-A: inhalation of long-acting $\beta_{2}$-agonist; $s \beta_{2}$-A: inhalation of short-acting $\beta_{2}$-agonist; $\mathrm{AH}$ : antihistamines. 
rapidly reversible: at the third measurement, $15 \mathrm{~min}$ after the provocation, they had a mean increase in FEV1 of $6 \%$. Only two patients had a further decrease in FEV1 after 5 min, (2.7 and 5\%). One patient having an $8 \%$ fall after the UNDW-inhalation, had a $15 \%$ fall in FEV1 at the third measurement. In the control group the minimum fall in $\mathrm{FEV} 1$ was $0 \%$ and the maximum was $5.2 \%$ (figs. 1 and 2).

A positive response to HS was noted in 15 out of 18 patients. Three asthmatic patients did not respond after the cumulative $15.5 \mathrm{~min}$ inhalation time. After the first 0.5 min of inhalation, a $24-26 \%$ fall FEV1 was observed in four asthmatics. The maximum fall (34\%) was observed in one patient after the following $1 \mathrm{~min}$ inhalation interval (fig. 3).

In the control group, all children completed the whole 15.5 min inhalation time (fig. 4). One subject responded with a $23 \%$ fall in FEV1 after the last inhalation step. For this child, a continuous decrease was observed (FEV1: $\left.2.72 \rightarrow 2.64 \rightarrow 2.56 \rightarrow 2.52 \rightarrow 2.48 \rightarrow 2.08 \mathrm{~L} \cdot \mathrm{s}^{-1}\right)$ and FEV 1 returned to baseline value after salbutamol inhalation.

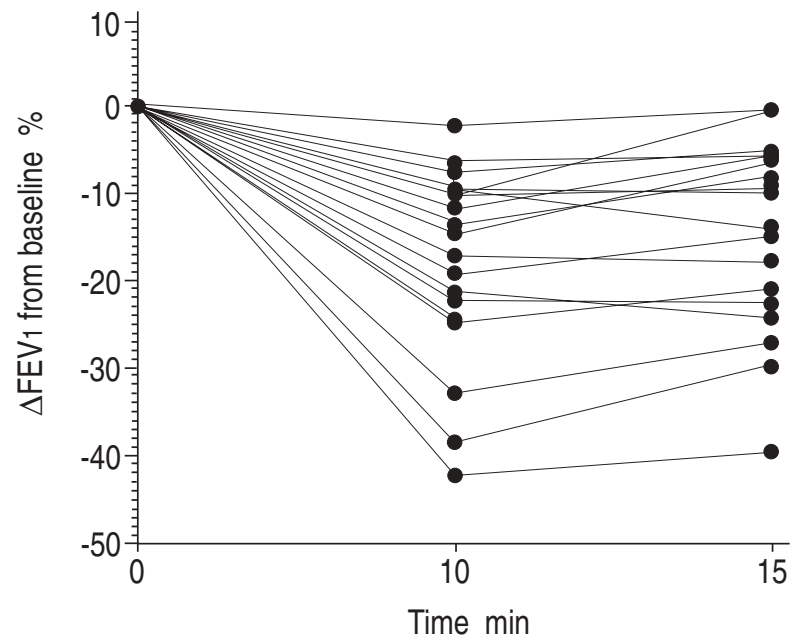

Fig. 1. - Change in forced expiratory volume in one second $(\triangle \mathrm{FEV} 1)$ from baseline in asthmatic children $(n=19)$ immediately after and 5 min after challenge with ultrasonically-nebulized distilled water (UNDW). Time $0=$ start of inhalation.

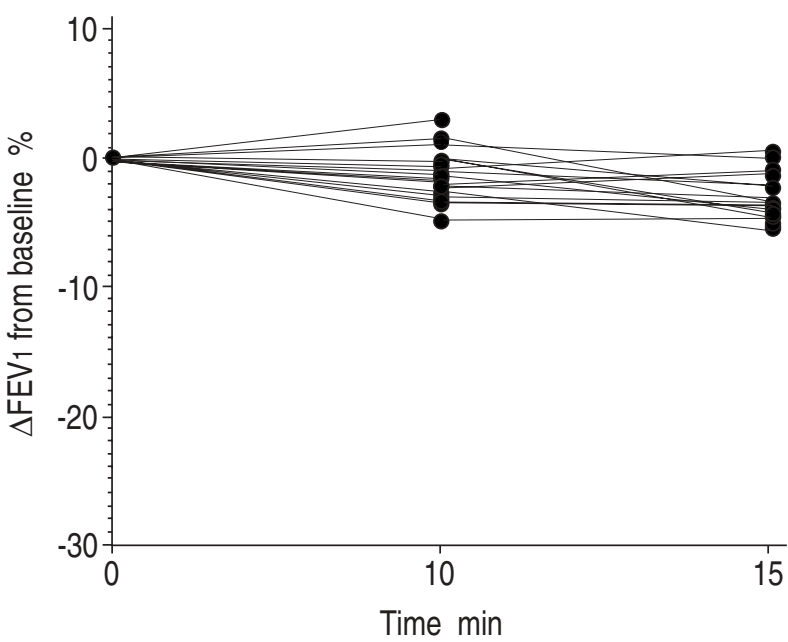

Fig. 2. - Change in forced expiratory volume in one second $(\triangle \mathrm{FEV} 1)$ from baseline in controls $(n=17)$ immediately after and 5 min after challenge with ultrasonically-nebulized distilled water (UNDW). Time $0=$ start of inhalation
His baseline FEV1 was $106 \%$ of predicted. He had no personal or family history of atopy, asthma or smoking, and no respiratory tract infection was apparent during the last 4 weeks. In another subject, having a $15 \%$ fall in FEV1 after the 1 min challenge step, without any clinical symptoms of bronchial obstruction, this $15 \%$ fall was interpreted as a measurement error and the challenge was continued. Subsequent FEV1 values improved and this subject was not considered to be a responder.

Bronchial provocation with HS appeared to be more sensitive, with 15 out of $18(83 \%)$ asthmatic patients responding, and slightly less specific (94\%) than UNDW, because one control subject reacted. There was a trend for UNDW to be less sensitive (68\%), because six asthmatics failed to respond (three of them also being missed by the HS provocation) but more specific (100\%), with no false positive result; however, the differences were not statistically significant. The odds ratio linking a positive response to asthma was 5.6 (95\% confidence interval (95\% CI) 2.7-11.9) for challenge with HS and $3.2(95 \%$ CI 1.9-5.4) for UNDW.

All patients having a PD15 of $0.8-3.5 \mathrm{~mL}$ (HS) also responded to the UNDW provocation (table 2). The three

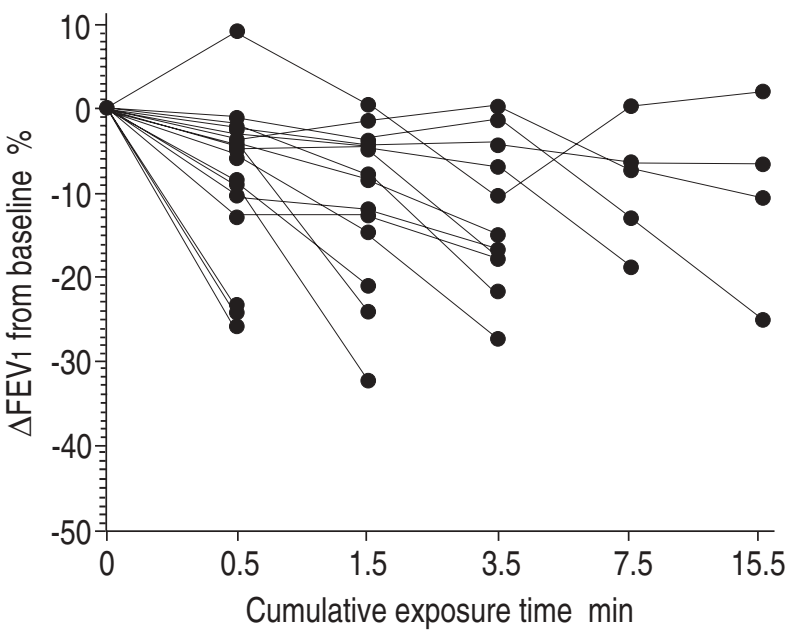

Fig. 3. - Change in forced expiratory volume in one second $(\triangle F E V 1)$ from baseline in asthmatic children $(n=18)$ after successive inhalations of hypertonic saline (HS) for $30 \mathrm{~s}, 1,2,4$ and $8 \mathrm{~min}$.

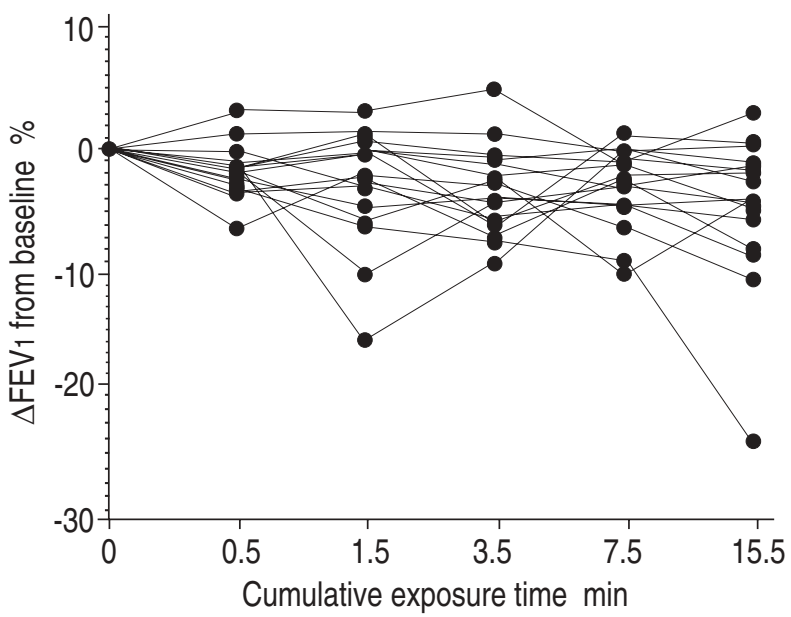

Fig. 4. - Change in forced expiratory volume in one second $(\triangle F E V 1)$ from baseline in controls $(n=17)$ after successive inhalations of hypertonic saline (HS) for $30 \mathrm{~s}, 1,2,4$ and $8 \mathrm{~min}$. 


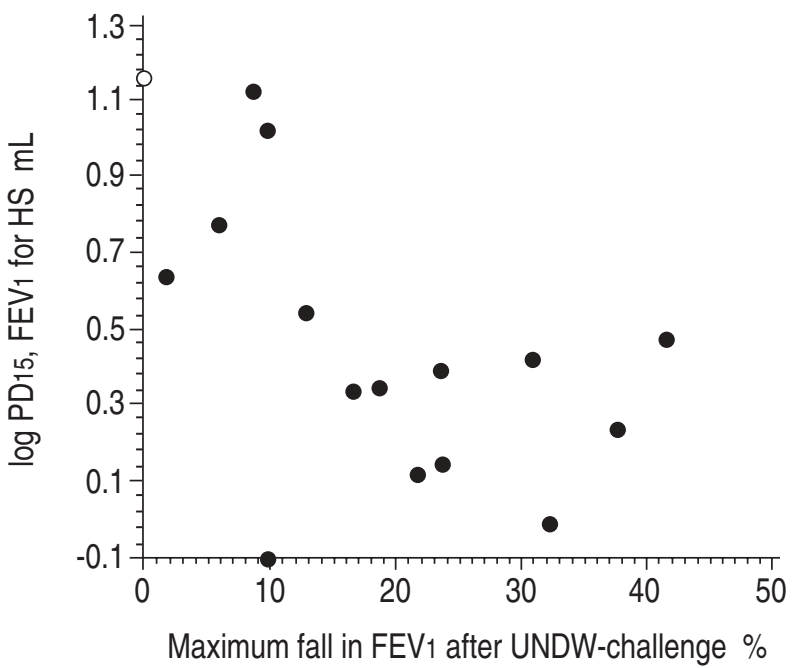

Fig. 5. - Correlation between dose of hypertonic saline (log-transformed) causing a fall in FEV1 of $15 \%\left(\log P D_{15}, F_{1} V_{1}\right)$ and the maximum fall in FEV1 from baseline after inhalation of UNDW for 15 asthmatic children $(\bullet)$, and one control subject $(\bigcirc)$, responding to HS. Three asthmatic children did not respond to HS, hence no PD15 could be calculated. HS: hypertonic saline; FEV1: forced expiratory volume in one second; PD15: provocation dose of HS cause a 15\% fall in FEV1; UNDW: ultrasonically-nebulized distilled water.

patients and one control subject responding only to HS had PD15 values of 4.2-14.4 mL. PD15 could not be calculated for four patients: one did not return for the HS provocation after having the UNDW challenge and three patients did not respond to HS (these three also failed to respond to UNDW).

The correlation between log PD15 in the HS challenge and the maximum fall in FEV1 after UNDW is shown in figure 5 for the 15 asthmatic patients and one control subject who had a positive response to HS. A statistically significant negative correlation for log PD15 after HS and the maximum fall in FEV1 after UNDW was obtained with the Spearman's rank correlation $\left(r_{s}=-0.63\right.$; $\mathrm{p}<0.005$ ). The correlation between maximum fall in FEV1 after HS and UNDW was $0.69(\mathrm{p}=0.0001)$.

In both groups, no significant correlation was obtained between response to the challenge and the asthma severity score (HS: $r_{s}=0.24 ; p>0.1$; UNDW: $\left.r_{s}=0.06 ; p>0.1\right)$.

\section{Discussion}

The results of the present study confirm the observations that both inhalation of UNDW and HS are effective bronchoconstrictor stimuli in children with mild-to-moderate asthma but not in control subjects. The aim of this study was not to compare two different nonisotonic aerosols but to test two well-established protocols [7, 13, 16] with regard to their utility in epidemiological studies, in order to make realistic recommendations as to which method should be used in further population-based studies. Criteria for an optimal test in such studies are: high safety; high sensitivity and specificity; high acceptability (particularly in children); and short duration.

Inhalation of nonisotonic solutions offers many advantages with respect to these demands as compared to inhalation of cold air, exercise or pharmacological challenges. Both protocols use minimal equipment, are relatively cheap, and require little patient co-operation. In a recent study, RIEDLER et al. [7] used HS challenge in 382 children aged 13-15 yrs, and found a sensitivity of $47 \%$ for current wheeze. Distilled water challenge has been reported to be of somewhat lower sensitivity by FRISCHER et al. [16], who found a sensitivity of $36 \%$ in 446 children aged 7-10 yrs. These observations were confirmed by the present study, showing a somewhat higher sensitivity for HS as compared to UNDW challenge. However, one asymptomatic control subject had a positive response to HS challenge without a personal or family history of atopy, asthma or smoking, and without an apparent respiratory tract infection in the last 4 weeks, resulting in a lower specificity for HS.

Apart from the provoking stimulus, different nebulizers were implemented. HS involved a multiple step protocol, whereas in UNDW challenge a single step protocol was used. Additionally, different cut-off points were used to assess the response. The Devilbiss nebulizer delivers approximately twice the amount of aerosol as compared to the Habel M608 nebulizer, which could lead to a higher dose of the provoking stimulus to the airways. However, for children responding to both stimuli, $0.8-3.5 \mathrm{~mL} \mathrm{HS}$ resulted in an average fall in FEV1 of $23 \%$, whereas 10 $\mathrm{mL}$ of UNDW resulted in an average fall in FEV1 of $22.8 \%$, suggesting that HS constitutes a stronger bronchoconstrictor than UNDW in children. It is unlikely that a multiple step protocol for UNDW would have increased the sensitivity to a large extent. In a previous study, we compared the single step protocol to a multiple step protocol and observed the maximum reaction after 2-6 min of inhalation [5]. In this study, the sensitivity of $10 \mathrm{~mL}$ UNDW inhalation was $67 \%$ and increased to only $75 \%$ after a total of $30 \mathrm{~mL}$ UNDW was inhaled. Furthermore, it is possible that during the $10 \mathrm{~min}$ inhalation period refractoriness has occurred in some patients, with FEV1 returning to baseline at the end of the inhalation. We cannot exclude the possibility that the smaller particle size delivered by the Devilbiss was responsible for the higher sensitivity of HS.

The disadvantages of the HS protocol are lower acceptability, longer duration and the need for a higher cut-off point. The probability of an "abnormal" result in a bronchial provocation test due to within-subject variability has been shown to increase with the number of measurements [23]. A higher cut-off point is needed in HS-challenge which involves up to six spirometric tests. Although in most children a dose response was observed for HS, four children reacted with a $>20 \%$ fall in FEV1 after 30 s of inhalation. Hence, the multiple step protocol does not exclude severe airway obstruction. However, after UNDW a considerable fall in FEV1 (38 and 42\%) was observed in two children. Hence, with regard to safety, the HS multiple step protocol offers an obvious advantage. For both challenge tests, resuscitation equipment should be at hand and only trained personnel should perform these tests.

There was a statistically significant correlation for PD15 (HS) and the maximum fall in FEV1 after UNDW tests, and both protocols identified the same children with asthma, which, conceptually, is what we would expect since a similar stimulus is exerted on the bronchial mucosa: a change in osmolarity of the airway surface liquid, causing the production and release of substances from cells in the airway epithelium and mucosa and resulting in airway narrowing [8]. 
A number of studies have investigated the relationship between nonisotonic aerosols and other challenge tests, particularly exercise and the inhalation of methacholine and histamine. In general, there is better agreement among indirect measures of BHR than between indirect and direct challenges. SMith and ANDERSON [4] found a significant relationship between HS and methacholine and exercise but not between distilled water and HS. This difference in observation might relate to the older age range of subjects studied by SMITH and ANDERSON [4]. RIEDLER et al. [7] found only a moderate agreement of response to HS and exercise, whereas MAKKER and Holgate [11] found a close relationship between HS responsiveness and the exercise-induced asthma score, and BELCHER et al. [12] found the response to exercise and hypertonic aerosols to be closely related. Several investigators observed a significant relationship between water and exercise $[9,10,24]$, whereas other investigators have not found a relationship between water and methacholine $[6$, 9, 10, 25]. MAKKeR and Holgate [11] found no correlation between HS and methacholine or histamine.

These observations stress the need for standardized challenge tests in population-based surveys in order to compare results between centres.

In conclusion, the results of this study suggest that there is a good correlation between the response to hypertonic saline and to ultrasonically-nebulized distilled water in children with mild-to-moderate asthma. There was a trend for bronchial provocation with hypertonic saline to be more sensitive than ultrasonically-nebulized distilled water for identification of children with clinical asthma. The challenge with ultrasonically-nebulized distilled water appeared to be slightly more specific and had a higher acceptability. However, for safety reasons, a multiple step protocol, such as that used in the hypertonic saline challenge, is preferable, particularly in field studies, in order to minimize the risk of severe airways obstruction.

\section{References}

1. Burney PG, Chinn S, Rona RJ. Has the prevalence of asthma increased in children? Evidence from the national study of health and growth, 1973-1986. BMJ 1990; 300 (6735): 1306-1310.

2. Pearce N, Weiland S, Keil U, et al. Self-reported prevalence of asthma symptoms in children in Australia, England, Germany and New Zealand. Eur Respir J 1993; 6 (10): 1455-1461.

3. Pattemore PK, Asher MI, Harrison AC, Mitchell EA, Rea HH. The interrelationship among bronchial hyperresponsiveness, the diagnosis of asthma, and asthma symptoms. Am Rev Respir Dis 1990; 142 (3): 549-554.

4. Smith $\mathrm{CH}$, Anderson SD. Inhalation challenge using hypertonic saline in asthmatic subjects: a comparison with response to hyperpnoea, methacholine and water. Eur Respir J 1990; 3: 144-151.

5. Eichler I, Götz M, Zarkovic J, Köfinger A. Distilled water challenges in asthmatic children. Chest 1992; 102: 753-758.

6. Galdes-Sebaldt M, McLaughlin FJ, Levison H. Comparison of cold air, ultrasonic mist, and methacholine inhalations as tests of bronchial reactivity in normal and asthmatic children. J Pediatr 1985; 107: 526-530.

7. Riedler J, Reade T, Dalton M, Holst D, Robertson C. Hypertonic saline challenge in an epidemiologic survey of asthma in children. Am J Respir Crit Care Med 1994; 150: 1632-1639.
8. Smith CM, Anderson SD. Inhalation provocation tests using nonisotonic aerosols. J Allergy Clin Immunol 1989; 84: 781-790.

9. Bascom R, Bleeker ER. Bronchoconstriction induced by distilled water: sensitivity in asthmatics and relationship to exercise-induced bronchospasm. Am Rev Respir Dis 1986; 134: 243-248.

10. Foresi A, Mattoli S, Corbo GM, Polidori G, Ciappi G. Comparison of bronchial response to ultrasonic nebulized distilled water, exercise and methacholine in asthma. Chest 1986; 90: 822-826.

11. Makker HK, Holgate ST. Relationship of the hypertonic saline responsiveness of the airways to exercise-induced asthma symptom severity and to histamine or methacholine reactivity. Thorax 1993; 48: 142-147.

12. Belcher NG, Lee TH, Rees PJ. Airway response to hypertonic saline, exercise and histamine challenges in bronchial asthma. Eur Respir J 1989; 2: 44-48.

13. Studnicka MJ, Frischer T, Weiss ST, Dockery DW, Speizer FE, Neumann MG. Seasonal and allergenic predictors of bronchial responsiveness to distilled water. Am Rev Respir Dis 1993; 146 (6, Pt1): 1460-1466.

14. Zach M, Polgar G, Kump H, Kroisel P. Cold air challenge of airway hyperreactivity in children: practical application and theoretical aspects. Pediatr Res 1984; 18 (5): 469-478.

15. Bardagi S, Agudo A, Gonzalez CA, Romero PV. Prevalence of exercise-induced airway narrowing in schoolchildren from a Mediterranean town. Am Rev Respir Dis 1993; 147 (5): 1112-1115.

16. Frischer T, Studnicka M, Neumann M, Götz M. Determinants of airway response to challenge with distilled water in a population sample of children aged 7 to 10 years old. Chest 1992; 102: 764-770.

17. American Thoracic Society Committee on Diagnostic Standards for Nontuberculous Disease. Definitions and clarification of chronic bronchitis, asthma, and pulmonary emphysema. Am Rev Respir Dis 1962; 85: 762-769.

18. Österr. Gesellschaft für Lungenerkrankungen und Tbc. Arbeitsgemeinschaft für Atemphysiologie: Empfehlungen zur Standardisierung der inhalat. Provokationen zur Messung der unspez. bronchialen Reaktivität. Prax Klin Pneumol 1986, 40: 356-364.

19. Donnelly WJ, Donnelly JE, Thong YH. Guidelines for maintenance treatment of childhood asthma: development of a score and system by multivariate cluster analysis. Soc Sci Med 1987; 24: 1033-1038.

20. American Thoracic Society. Standardization of spirometry: 1987 update. Am Rev Respir Dis 1987; Attachment 2: 1285-1298.

21. Zapletal A, Samanek M, Paul T. Lung function in children and adolescents: methods, reference values. Progr Respir Res 1987: 22: 113-218.

22. Riedler J, Robertson CF. Effect of tidal volume on the output and particle size distribution of hypertonic saline from an ultrasonic nebulizer. Eur Respir J 1994; 7 : 998-1002.

23. Strachan DP. Repeatability of ventilatory function measurements in a population survey of 7 year old children. Thorax 1989; 44: 474-479.

24. Daviskas E, Gonda I, Anderson SD. Local airway heat and water vapour losses. Respir Physiol 1991; 84: 115132.

25. Smith CM, Anderson SD, Black JL. Methacholine responsiveness increases after ultrasonic nebulized water but not after ultrasonic nebulized hypertonic saline. J Allergy Clin Immunol 1987; 79: 85-92. 